\title{
DEVELOPING AN EDUCATION WEB PORTAL FOR KNOWLEDGE SHARING AND CAPTURING
}

\author{
${ }^{1}$ S.Rajalakshmi, ${ }^{2}$ Dr.R.S.D.Wahida Banu \\ ${ }^{1}$ Lecturer/CSE, Velalar College of Engineering \& Technology, Thindal, Erode. \\ ${ }^{2} \mathrm{HOD} / \mathrm{ECE}$, Government College of Engineering,Salem \\ E-mail : 'mrajisIm@gmail.com
}

\section{Abstract}

An institute represents the ultimate knowledge organization. However, many researchers are not aware of the research activities within their own Colleges/institution. This often leads to redundancy in areas of research as well as reduced innovation and productivity since they are not aware of the available expertise and resources that could greatly contribute to their own research endeavors. Knowledge management represents a systematic means of acquiring, sharing, and using knowledge effectively within an Organization.

This paper explores web-based systems to connect researchers using knowledge management methodologies via a web-based portal. An attempt is made to build an educational Organization knowledge portal, to fill a perceived gap in knowledge sharing and accessibility within an organization. Here, sharing and capturing an individual's knowledge via web portal for the beneficiary of that institution. So, since switch over are made frequent, this type of Knowledge Portal System helps the students and the faculty members in the institution helps to access the other's knowledge for their improvement in academic.

This portal has the possibilities of a member registration, submitting news with some admin policies, sharing news or forums, download or upload articles and so on. The information's is made friendly sharing among the staff members or students only who joins this knowledge portal domain. The News can be published only when the admin rights are properly given by the administrator. This is because to avoid publishing unwanted news in this domain. The news can be of general information about the college, functions in the college, giving awareness about particular topic / conferences etc. This portal is developed by using PHP, Ajax and My Sql databases.

By this, students get necessary information about various departments and departmental Activities, Curriculum, Lecture notes of an experienced staff members, References, Useful URL links, White papers, Discussion forum, Wiki's and so on. In every higher educational institution such as in Engineering Streams, Teaching Staff members don't get an effective knowledge share tool to create and share their knowledge base among themselves and with student communities. So, this paper will help to develop a knowledge share tool to improve effective Teaching - Learning Process effectively in any Educational Institution.

Key words: Knowledge Management, Web based Portal, Information Sharing, Information Capturing, Engineering Colleges, Students and Staffs, database.

\section{INTRODUCTION}

Web portals can serve as powerful tools to help knowledge organizations, such as universities, colleges and improve their collaborative activities. They can facilitate knowledge acquisition, sharing, and discovery by allowing people to publish documents, share ideas, work collaboratively, and store information and knowledge in easily searchable repositories. Portals are becoming an increasingly important part of the information technology infrastructure of universities as they seek to integrate the vast intellectual resources within a central virtual space that is easily accessible via a web interface [3].

This paper explores the process of understanding knowledge needs in the research arena and transforming those needs into a web-based research Knowledge portal. The paper describes the development process, lessons learned from the experience, and future directions to make this portal a valuable Knowledge management tool for the university/any educational Institution.
Knowledge starts as Data raw facts and numbers. Information is data put into context. Information is readily captured in documents or databases. When Information is combined with experience and judgment, it becomes knowledge. Knowledge can be broadly classified as

, Explicit knowledge which is documented information that can facilitate action.

, Tacit knowledge which is the know-how and learning embedded in the minds of people in an organization. It involves perceptions, insights and experiences.

Academic Institutions grow and revitalize themselves through the knowledge they create, their processes for passing that knowledge on to others and the exchanges and relationships they foster among people. Knowledge management in academics can be thought of as a framework or an approach that enables people within the institute to develop a set of practices to collect information and share what they know, leading to action that improves services and outcomes. Knowledge management brings 
together three core organizational resources people, processes and technologies to enable an organization to use and share information effectively.

The power of knowledge management is that it maintains focus on people on faculty, staff and students and their needs. It is people who manage knowledge, and it is the role of organizations to promote processes with the help of technology so that people want to share and manage knowledge effectively.

Components of a Knowledge Management System A Knowledge Management System in its initial stages can be broken into several subcomponents:

Repositories: Repositories hold explicated formal and informal knowledge and the rules associated with them for accumulation, refining, managing, validating, maintaining, annotating and distributing content.

Collaborative Platforms: Collaborative Platforms support distributed work and incorporate pointers, skills databases, expert locators and informal communications channels. Networks: Networks support communications and conversation. They include leased lines, the intranet, the extranets, shared spaces, forums and exchanges (live $\&$ teleconferenced). Culture enablers that encourage sharing and use.

The transfer of knowledge from one person to another is the simple concept of Knowledge Management. The person receiving the knowledge benefits and learns from the experiences of the knowledgeable person. For example, a student in college learns from his experienced faculty...this is the transfer of knowledge. Knowledge management today can be seen as a technology where knowledge is transferred using collaborative environments and delivered to people when and where it is needed.

\section{RELATED WORK}

In order to Create an effective learning experience, a learning Content Management System has been developed. This can be achieved by using the Ontologies or by Semantic web. In this the Scholar made an idea to meet all the requirements for the sharing of knowledge in between faculty members and students of a college. [1][2]

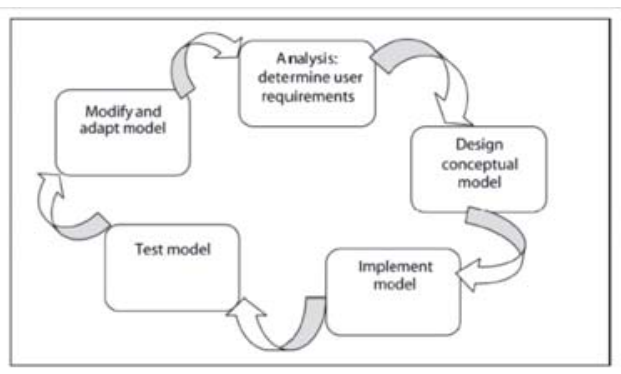

Fig. 1. System analysis and design life cycle
Thus designed and launched portals are made useful to search the researcher's papers, their lecturer notes on the particular topic or subject, Wiki's etc. This research papers can be made viewed by the student by giving some policy restrictions. By these inputs in the form of Lecturers, discussions, deliberations and demonstrations an entity relationship diagram (Figure 2) has been developed in order to understand how the entities within the information system would work together. This information is later used in the development of the dynamic databases. A flowchart has been developed to depict the organization for the site. Given the potential complexity of a portal, a clean, simple, user-friendly organizational design is critical to the project's success.

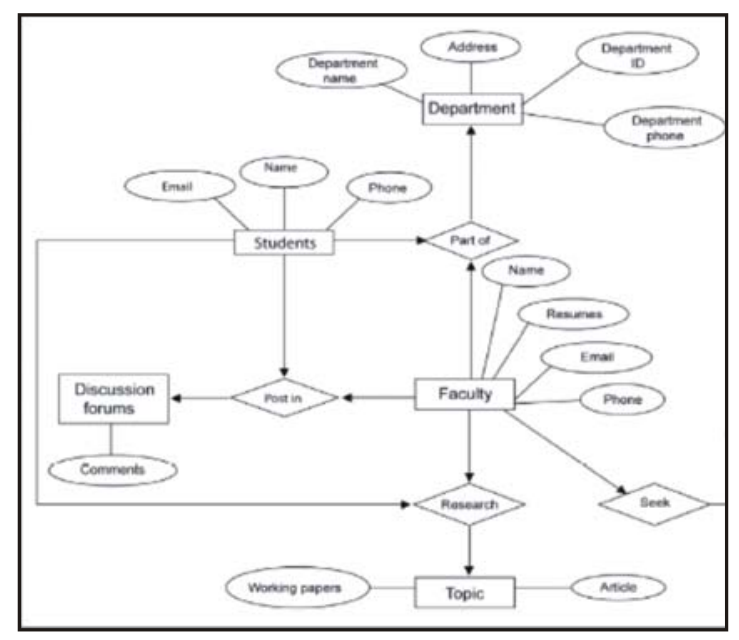

Fig. 2. Entity relationship diagram for the research knowledge portal

\section{SYSTEM ARCHITECTURE}

Thus Proposed and developed system architecture for Knowledge Capturing \& sharing, is shown in fig 3 .

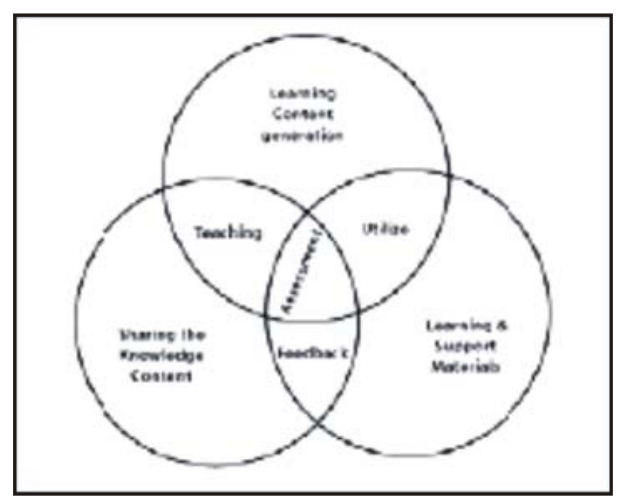

Fig. 3. System Architecture

This Architecture is designed by using PHP with Ajax and the database used is My Sql .Here we considered five colleges in and around an area. . The staff from various 
colleges is made to register in the Knowledge Portal Community and they are allowed to share their documents, Papers, Forums \& News etc through this Portal. The web-based publishing feature allows individuals to use a template or a set of templates approved by the administrator, as well as wizards and other tools to create or modify web content. The format management feature allows documents including legacy electronic documents and scanned paper documents to be formatted into HTML or Portable Document Format (PDF) for the website. So, the best community practice can be effectively shared by others.

The revision control feature allows content to be updated to a newer version or restored to a previous version. Revision control also tracks any changes made to files by individuals. An additional feature is indexing, search, and retrieval. A Knowledge Portal system indexes all data within a staff community. Individuals can then search for data using keywords, with the options given in the Portal."

The summary of the research work may include:

1. Searching of Research portals

2. Effective Research

3. Develop Interactive Model of Portals

4. Build Portal Prototype

5. Portal Demonstration

One of the example of a CMS (Content Management System) is as follows:

"A Content Management System (CMS) is a system used to manage the content of a website. Typically, a CMS consists of two elements: the Content Management Application (CMA) and the Content Delivery Application (CDA). The CMA element allows the content manager or author, who may not know Hypertext Markup Language (HTML), to manage the creation, modification, and removal of content from a website without needing the expertise of a webmaster. The CDA element uses and compiles that information to update the website. The features of a CMS system vary, but most include webbased publishing, format management, revision control, and indexing, search, and retrieval.

The Overview of the Knowledge Portal outlet for registering the Users is as shown below:
Fig. 4.Outline view of the Knowledge Portal

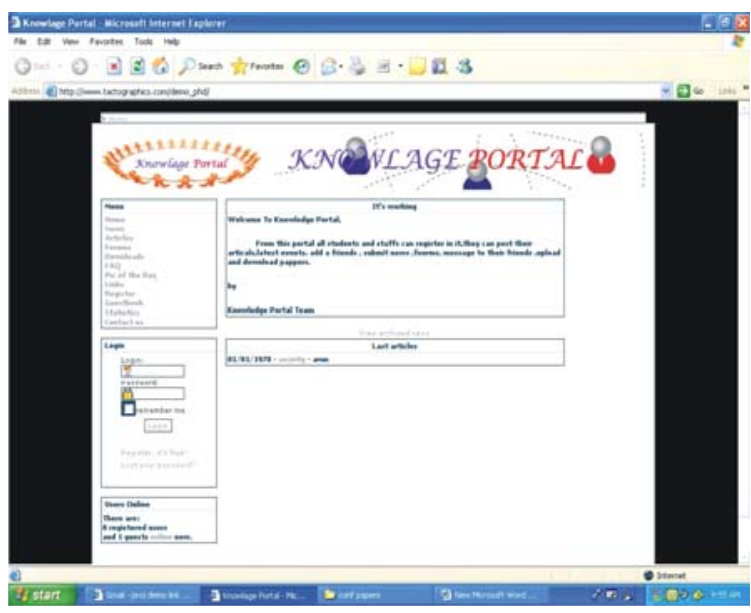

Here, the Knowledge base contents are the knowledge of the experienced staff of an institution, their subject materials, conference papers, etc which will be mined by using a MySql Server and helpful for the staff who works in other institution. Here, this portal has an option to join with this community by registering free in this web site to post news, articles, Forums, and any important event which is to be held in their department or in their college. This will make useful to share the news or any Knowledge between staff and students who also can join with this community. This will help the students to post Queries about any topic to a particular registered person who is strength in an particular area.

\section{LITERATURE REVIEW}

\section{A. Web portals in higher education}

What is a portal? An internet portal is 'a single integrated, ubiquitous, and useful [point of] access to information (data), applications, and people' (IBM Global Education Industry, 2000). More than simply an archive of information, portals facilitate a dynamic exchange of knowledge, data, and information. By compiling content from multiple sources, they limit redundancy and efficiently increase the dissemination of information.

The most recent application of portals in higher education has been to create a point of access for administrative functions for students, such as registration, financial aid, and academic records, or for staff, such as time sheets, leave balances. In this way, the use of portals maximizes efficient use of staff and students' time.

Portals have become more than convenient launch pads for Internet searchers. Today's Portals are increasingly secured applications designated to give users simple, quick ,secure access to relevant Organizations \& Personal data. [3] 
They further suggest that portals represent new strategic means of increasing a university's competitive position by fostering innovation and research activities that can lead to greater acquisition of grants and improved prestige for the university. By harnessing the ability of portals to create learning and research communities, portals can further leverage the huge intellectual capital contained within the organization via collaborative, synergistic activities.

Portals also serve to empower individuals within a more broadly defined university community. By providing easy accessibility to both explicit and tacit knowledge as well as communities of practice, people are not constrained by geographic or other physical barriers in terms of communicating and exploring new knowledge:

Portals facilitate knowledge transfer through the inclusion of multiple communication channels, such as message boards and directories, moving beyond the onesided Information exchange found in traditional websites [5].

B. Impact of Social Networks for Knowledge sharing/ coding/capturing

In Social Networks, the relationship is made frequent between the web and people by computer moderated discussions. This conversation is made to take place on line, over an intra-net or private Internet forum.

\section{A. What can Social Networks provide?}

The social network is being realized to carry out information sharing among the staff members distributed in various colleges. A social network can be modeled as a graph with nodes representing people or groups, and links representing relationships or information flows between nodes. With advancements in technology the following services and advantages are as follows:

- Making knowledge available to people at right time.

- Connect people and build relationships across various educational institutions.

- Better knowledge exchange platform.

- Capture ideas and encourages brainstorming.

- Change from knowledge-sharing to collective knowing.

- Provides access to social capital.

- This power of social networks makes them excellent platform for knowledge sharing and enhancing technological development schemes.

\section{B. Social Barriers to Knowledge Transfer}

Knowledge management is comprised of the phases or activities of knowledge generation, transfer, accumulation, adoption, and diffusion. Knowledge transfer means sharing of knowledge between different groups working within same domain of objective. Some common hindrance to knowledge sharing within these communities from social point of view are:

- Language conflicts arising due to geographical disparities.

- Conflict Avoidance and conservation attitude of those at the top of the hierarchy.

- Bureaucracy and Hierarchy that might impose formal procedures and prevent cross-sectional promotion of knowledge.

- Lack of coherence between personal and organizational strategies.

C. Communication Blogs:

- Each person has his or her own ideas and does not copy those of his/her neighbor

- No one dominates the conversation.

- People make thoughtful insightful statements since they have time to reflect.

- People can read all the comments of the other people and then make general or specific reaction comments.

- Often when a person writes very insightful statement, others become aware of being more insightful.

- The blog "conversations" are on topic.

- The initial blog helps to serve an assessment of the participants' level of knowledge about the topic.

- People can go back to their earlier blogs and see what they thought at the beginning of blog and then see what they think about the topic at the end of the professional development.

- Also, blogs can be used to distribute common word processing documents such a form that you all will work on during the professional development.

Advantage of Blogs, wikis, podcasts, and other powerful web tools for classrooms include the following:

- Can promote critical and analytical thinking.

- Can promote creative, intuitive and associational thinking (creative and associational thinking in relation to blogs being used as brainstorming tool and 
also as a resource for interlinking, commenting on interlinked ideas).

- Can promote analogical thinking.

- Potential for increased access and exposure to quality information.

- Combination of solitary and social interaction.

Difference between Blogs and Discussion Forums:

- Discussion fora are predominantly shared community spaces in which individual voices may make themselves heard but are afforded no specific space of their own.

- First and foremost, blogs provide a platform for individual expression and also support reader commentary, critique, and interlinkage as subsequent steps.

- In other words, blogs foreground the individual, while discussion forum foreground the group. The suggestion here is that this makes blogs the more useful tool, especially in cases where there is no strong sense of group belonging or loyalty, or there is a lack of group turn-taking and communication skills."

D. Giving EducationAwareness/Program:

Now a days, they are not willing to share their tacit Knowledge with their own friends.

- Implementing a successful Awareness Program is an essential step in enhancing security within any organization. The mindset and behavior of staff is the current issue - in order to operate at an acceptable level of awareness the organization's staff must have certain basic knowledge to behave 'securely'. By giving such Awareness the importance sharing information between Staff members and Students within various Organizations will lead to bridge a gap between them.

\section{E. Exchanging of Circulars and Communication:}

- By exchanging of circulars, the activities in one organization will be shared by another organization.

- This communication between the organizations will lead to a non profit information sharing. That will be very useful for the staff members and students to gain Knowledge of preparing various circulars for various activities.

Cost Principles for Educational Institutions:

1. Purpose

2. Supersession

3. Applicability.

4. Responsibilities

5. Attachment
6. Effective Date

7. Inquiries

F. Sharing National and International days:

- By this sharing, the members registered in the portal community come to know about the National and International days, any other functions related to our Nation.

G. The role of knowledge management in higher education:

Education portals create a common gateway to the data and services that the people throughout the university need to effectively share information and work together on projects. Education portals can be built on technologies you may already have-such as Some of the things you can do with a portal include:

- Record and share grades with students electronically

- Create online communities for students, faculty, administrators, and alumni to collaborate

- Facilitate sharing of best practices among faculty and administrators

- Enable students, faculty, administrators, and alumni to access your institution's resources anytime from any connected device

- Post lesson plans, coursework, research content, and more to online document libraries

- Provide Web-based class registration, tuition and financial aid payments, and other services

- Create dashboards that show up-to-date student performance data to inform instruction and decisions

- Share information with your board of directors and community members.

\section{Key Benefits}

Portal solutions can help us to:

- Increase student engagement. Give students easy ways to connect with their professors and their peers to get them more engaged in their classes.

- Facilitate anytime, anywhere learning. Provide your students with single sign-on access to learning materials and campus resources-from library content to complete online courses-at any time, from virtually anywhere, and from any type of connected device. We can create a virtual campus that never closes.

- Make better decisions. Inform routine decisions and long-range strategic planning across all business 
functions and disciplines with accurate, readilyavailable data presented in intuitive and familiar formats.

- Let faculty focus on research and instruction. Make it easier for your faculty to find instructional resources; assess students; record and track grades; and communicate with their colleagues and students, and they will have more time and energy to focus on important research and facilitate meaningful learning experiences that meet the unique needs of individual students.

- Streamline administrative tasks. Make it easy for students to register for classes, access financial aid information, pay their tuition, sign-up for lunch programs, report absences, and more from any computer. Connect with your community.

- By proving simple and customized ways to access information and connect with your institution, you can reap the benefits of strong connections with alumni and other members of the broader community.

- The concept of knowledge management may be new, institutions of higher education have been creating and sharing knowledge they have existed, through research and teaching.

- Faculty participates in knowledge transfer internally, within their respective departments, and externally, through their communities of practice.

- As public, private, and for profit higher education institutions alike respond to the phenomenal growth of online courses, cyber colleges, and virtual universities, these same reasons to adopt KM apply.

- It is with KM that colleges will be better able to increase student retention and graduation rates; retain a technology workforce in the face of severe employee shortages; expand new web based offerings; work to analyze the cost effective use of technology to meet more enrollment; transform existing transaction-based systems to provide information, not just data, for management; and compete in an environment where institutions cross state and national borders to meet student needs anytime/anywhere. This will lead to better accreditation by appropriate bodies.

\section{DISCUSSION AND CONCLUSION}

The need for knowledge acquisition and knowledge sharing is readily acknowledged across the institution. In meetings with faculty and administrators, the approach for a web-based knowledge system is greatly needed to facilitate collaboration efforts across and within the different academic areas. The faculty focused primarily on website usability issues. The main objective is to integrate the knowledge management practices and e learning together for developing an effective knowledgesharing platform between teachers and students. This is to see improvements in their self-learning attitude and academic performance.

Thus this web portal for the educational institution will be an effective resource sharing of knowledge between faculty members and students and will provide necessary needed information for students to improve their academic performance and excellence.

\section{REFERENCES}

[1] Cronin, B. (2001) 'Knowledge management, organizational culture and Anglo-American higher Education', Journal of Information Science, Vol. 27, No. 3, pp.129-137.

[2] Daigle, S.L. and Cuocco, P.M. (2002) 'Portal technology opportunities, obstacles, and options: a view from the California State University', Web Portals and Higher Education, Technologies to Make IT Personal, Boulder, CO: Educause, pp.109-123, Retrieved 10 January 2005, http: //www.educause.edu/ir/library/html/pub5006.asp

[3] Katz, R.N. et al. (2002) Web Portals and Higher Education, Technologies to Make IT Personal, Boulder, CO: Educause, Retrieved 10 January 2005, http://www.educause.edu/ir/library /html/pub5006.asp

[4] Milam, Jr., J.H. (2001) 'Knowledge management for higher education', ERIC Digest, Washington, DC: ERIC Clearinghous on Higher Education, Retrieved via ERIC, University of Maine, 5 January 2005, www.library.umaine.edu

[5] Pickett, R.A. and Hamre, W.B. (2002) 'Building portals for higher education', New Directions for Institutional Research, Vol. 113, pp.37-55.

[6] Svarre, K. (2002) 'Content management system', SearchWebServices.com, March, Retrieved 7 February 2004, http://searchwebservices. techtarget.com/sDefinition/0,sid 26_gci508916,00 .html>

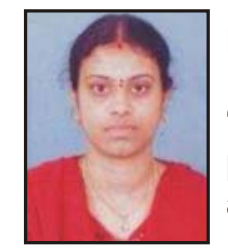

Ms.S.Rajakshmi, M.E(CSE) in Anna University, and her research area is "Knowledge Engineering". She has presented several papers in National and International Conferences. 